Check for updates

Cite this: J. Mater. Chem. A, 2021, 9, 23631

Received 2nd August 2021

Accepted 1st October 2021

DOI: $10.1039 / \mathrm{d} 1 \mathrm{ta0} 6530 \mathrm{k}$

rsc.li/materials-a

\section{Sorption-enhanced mixed-gas transport in amine functionalized polymers of intrinsic microporosity (PIMs) $\uparrow$}

\author{
Katherine Mizrahi Rodriguez, (D) $\ddagger^{a}$ Francesco M. Benedetti, (ID $\ddagger^{b}$ Naksha Roy, (D) b \\ Albert X. Wu iD ${ }^{b}$ and Zachary P. Smith iD *b
}

\begin{abstract}
Pure-gas transport performance rarely matches mixed-gas performance for industrially relevant membrane applications. While significant effort has focused on studying the adverse effects of plasticization, an additional phenomenon known as competitive sorption can be used to improve performance, resulting in mixed-gas permselectivities that far exceed pure-gas predictions. Such findings are rare, but recent synthetic discoveries of functional polymers of intrinsic microporosity (PIMs) now provide a platform to investigate if competitive sorption effects can improve separation performance in complex mixtures by offsetting the adverse effects of plasticization. In this work, we report high-pressure and mixed-gas transport properties for six PIMs with identical benzodioxane backbones and a diverse set of backbone functionalities. Low-pressure mixed-gas tests revealed a relationship between $\mathrm{CO}_{2}$ sorption affinity of the PIMs and improvements in $\mathrm{CO}_{2} / \mathrm{CH}_{4}$ and $\mathrm{CO}_{2} / \mathrm{N}_{2}$ mixed-gas permselectivity compared to pure-gas scenarios. The amine-functionalized PIM-1 $\left(\mathrm{PIM}-\mathrm{NH}_{2}\right)$ showed an unprecedented $140 \%$ and $250 \%$ increase in equimolar $\mathrm{CO}_{2} / \mathrm{CH}_{4}$ and $\mathrm{CO}_{2} / \mathrm{N}_{2}$ mixed-gas permselectivity, respectively, compared to that of pure-gas tests at $2 \mathrm{~atm}$. Additionally, $\mathrm{PIM}-\mathrm{NH}_{2}$ retained high $\mathrm{CO}_{2} / \mathrm{CH}_{4}$ mixed-gas permselectivity (>20) up to pressures of $26 \mathrm{~atm}$ in $50 / 50 \mathrm{CO}_{2} / \mathrm{CH}_{4}$ mixtures, demonstrating a resistance to plasticization. Pure-gas sorption and mixed-gas permeation for the six PIMs were compared to elucidate structureproperty relationships. Results demonstrate the remarkable potential of primary amine functionalization for developing highly sorption-selective and plasticization-resistant membranes for gas separations.
\end{abstract}

\section{Introduction}

Global $\mathrm{CO}_{2}$ emissions reached over $30 \mathrm{Gt}$ in 2020, while U.S. natural gas consumption has increased by approximately $30 \%$ in the past decade. ${ }^{\mathbf{1}}$ In the U.S. chemical industry alone, about $50 \%$ of the energy consumption results from heat-intensive processes such as distillation and absorption, which also produce indirect GHG emissions. ${ }^{2}$ As such, implementing energy-efficient separation alternatives and carbon capture solutions is critical to meet the U.S. Department of Energy's emission reduction target of $80 \%$ by $2050 .{ }^{3}$ Unlike traditional unit operations, polymer membranes have a small, modular footprint and facile operation, and do not require toxic solvents or regeneration. ${ }^{4}$ However, polymer performance is limited by

\footnotetext{
a Department of Materials Science and Engineering, Massachusetts Institute of Technology, Cambridge, Massachusetts 02139, USA

${ }^{b}$ Department of Chemical Engineering, Massachusetts Institute of Technology, Cambridge, Massachusetts 02139, USA. E-mail: zpsmith@mit.edu

$\dagger$ Electronic supplementary information (ESI) available. See DOI: $10.1039 / \mathrm{d} 1 \mathrm{ta} 06530 \mathrm{k}$

\$ These authors contributed equally.
}

a trade-off between permeability and selectivity, which is defined by a theory that does not consider mixture effects. ${ }^{5,62}$

Since 2004, microporous polymers such as polymers of intrinsic microporosity (PIMs), ${ }^{6}$ thermally rearranged (TR) polymers, ${ }^{7}$ ROMPs, ${ }^{8}$ and CANALs $^{9}$ have shown noteworthy performance enhancements. Benzotriptycene-based PIMs, for instance, redefined pure-gas $\mathrm{CO}_{2} / \mathrm{N}_{2}$ and $\mathrm{CO}_{2} / \mathrm{CH}_{4}$ upper bound benchmarks in 2019. ${ }^{10}$ Additional upper bounds for $\mathrm{H}_{2}$-based separations, ${ }^{\mathbf{1 1}}$ and gas mixtures ${ }^{\mathbf{1 2}}$ have been reported, where microporous polymers continue to outperform traditional polymers. Microporous polymers are designed with rigid monomers of high configurational free volume (e.g., spirobisindane and triptycene), which result in inefficiently packed solid-state structures with high internal surface areas, intrachain rigidity, and excellent permeability-selectivity combinations. ${ }^{13-16}$ However, their intrachain rigidity alone has been insufficient to mitigate plasticization effects at high pressures. ${ }^{17,18}$

Another important aspect required for industrial deployment of PIM-based membranes is understanding performance for complex mixtures. To this end, several groups have been investigating mixed-gas sorption for $\mathrm{CO}_{2} / \mathrm{CH}_{4}, \mathrm{CO}_{2} / \mathrm{C}_{2} \mathrm{H}_{4}$, $\mathrm{CO}_{2} / \mathrm{N}_{2} \mathrm{O}$, and $\mathrm{CO}_{2} / \mathrm{C}_{2} \mathrm{H}_{6}$ mixtures in various polymers, 
including TZ-PIM,${ }^{19}$ PIM- $1,{ }^{19}$ PTMSP,${ }^{19}$ AO-PIM,${ }^{20}$ 6FDA-mPDA,${ }^{21}$ PIM-Trip-TB, ${ }^{22}$ 6FDA-HAB and its TR450 analogue, ${ }^{23}$ cellulose triacetate (CTA), ${ }^{24} \mathrm{PDMS}^{25,26}$ 6FDA-TADPO, ${ }^{27} \mathrm{PEO},{ }^{28}$ and PMMA. ${ }^{29,30}$ Sorption of complex $\mathrm{C}_{2} \mathrm{H}_{6} / \mathrm{CO}_{2} / \mathrm{CH}_{4}$ ternary mixtures in PIM-1 has also been recently reported, highlighting the importance of competition in influencing transport performance under realistic conditions. ${ }^{31}$ Mixed-gas sorption studies demonstrate that gases with high polymer affinity (e.g., $\mathrm{CO}_{2}$ ) can reduce the sorption of co-penetrants in a gas mixture, increasing sorption selectivity and permselectivity in separations such as $\mathrm{CO}_{2} / \mathrm{CH}_{4}$ and $\mathrm{CO}_{2} / \mathrm{N}_{2}$. In pristine polymers at high pressures, however, plasticization effects can decrease diffusion selectivity and permselectivity beyond improvements achieved by competition effects. ${ }^{23}$ This trade-off is particularly acute for diffusion-selective polymers including polyimides and PIMs. ${ }^{23}$

Recently, Eddaoudi and Koros have demonstrated that chemical functionality can be used to simultaneously improve sorption selectivity and plasticization resistance in MOF-based mixed-matrix membranes. ${ }^{32,33}$ When considering condensable penetrants (i.e., $\mathrm{H}_{2} \mathrm{~S}$ and $\mathrm{CO}_{2}$ ) in these MMMs, competitive sorption can improve $\mathrm{H}_{2} \mathrm{~S}$ and $\mathrm{CO}_{2}$ permeation, while controlled plasticization at high pressures can retain good $\mathrm{CO}_{2} / \mathrm{CH}_{4}(>20)$ and $\mathrm{H}_{2} \mathrm{~S} / \mathrm{CH}_{4}(>30)$ permselectivities. Related findings have also been reported for transport of binary mixtures in polymer films. One notable example relates to $-\mathrm{OH}$ modified PIM-polyimides (PIM-PIs), where Swaidan et al. and Alghunaimi et al. reported the syntheses of hydroxyl bearing PIM-PIs, TPDA-APAF ${ }^{34}$ and TDA1-APAF, ${ }^{35}$ respectively, which showed $11 \%$ and $17 \%$ higher mixed-gas $\mathrm{CO}_{2} / \mathrm{CH}_{4}$ permselectivities compared to pure-gas tests, respectively. Plasticization resistance improved in these PIM-PIs due to interchain rigidity provided by hydrogen bonding.

A related approach to increase sorption selectivity involves post-synthetic functionalization of the polymer backbone. ${ }^{36,37}$ Several functionalized variants of PIM-1 have been reported, including the incorporation of tetrazole ${ }^{38}$ carboxylic acid, ${ }^{39-42}$ amidoxime, ${ }^{38}$ thioamide, ${ }^{43}$ amine,${ }^{44}$ and amide ${ }^{45}$ groups. In these examples, however, functionalization has consistently resulted in reduced free volume and correspondingly low puregas permeabilities. With respect to sorption, most functionalized PIMs show moderate changes in $\mathrm{CO}_{2}$ uptake, with the exception of amine-functionalized PIM-1 $\left(\mathrm{PIM}-\mathrm{NH}_{2}\right) \cdot{ }^{\mathbf{4 4 , 4 6}}$ Unfortunately, however, pure-gas performance for $\mathrm{PIM}-\mathrm{NH}_{2}$ is significantly below the 2008 upper bound ${ }^{47}$ and mixed-gas transport has not been studied. Given the extensive palette of post-synthetic chemistries available to PIMs, understanding how functionality affects mixed-gas performance and competition is crucial for the design of high-performing microporous membranes for industrially relevant conditions.

Herein, we elucidate direct structure-property relationships between polymer chemistry, sorption affinity, and mixed-gas competition effects for six functionalized PIM-1 derivatives. Mixed-gas sorption was modelled from pure-gas isotherms to assess the role of competitive sorption on mixed-gas permeation for $\mathrm{CO}_{2}$-based separations under industrially relevant feed compositions. Pure- and mixed-gas high-pressure permeation tests were also considered to evaluate the role of polymer functionality on plasticization. Sorption selectivity and mixed-gas permeability enhancements of these PIMs were compared to reported literature for microporous polymers, revealing that PIM$\mathrm{NH}_{2}$ had the most improved competitive sorption properties among known PIMs. Additionally, $\mathrm{PIM}^{-\mathrm{NH}_{2}}$ showed an exceptional resistance to plasticization compared to PIM-1. These results underscore the promise of primary amine functionalization for significantly enhancing mixed-gas sorption selectivity and maintaining excellent separation performance at high pressures.

\section{Experimental}

\section{Materials and film preparation}

PIM-1 analogues with chemical moieties including nitrile $(-\mathrm{CN}$, PIM-1), carboxylic acid (-COOH, PIM-COOH), amine $\left(-\mathrm{CH}_{2} \mathrm{NH}_{2}\right.$, PIM-NH ${ }_{2}$ and PIM-deBOC(acid)), tert-butoxycarbonyl $\left(-\mathrm{CH}_{2}\right.$ $\mathrm{NHCOOC}\left(\mathrm{CH}_{3}\right)_{3}$, PIM- $\left.t \mathrm{BOC}\right)$, and partial urea (-NHCONH-, PIM-deBOC(thermal)), represented in Fig. 1, were synthesized or chemically functionalized as described in our previous work. ${ }^{\mathbf{4 0 4 8}}$ Methanol (HPLC, $\geq 99.9 \%$ ) was purchased from Sigma Aldrich and used as received. $\mathrm{PIM}-\mathrm{NH}_{2}$ derivatives including PIM-deBOC(thermal), PIM-deBOC(acid), and PIM- $t$ BOC were soaked in methanol for $24 \mathrm{~h}$ and dried under vacuum at $130{ }^{\circ} \mathrm{C}$ for $12 \mathrm{~h}$ prior to all characterization tests. $\mathrm{PIM}-\mathrm{COOH}$ samples were not methanol treated due to structural fragility when submerged in methanol. To enable robust comparison between samples, PIM-1 films were prepared with and without methanol treatment. Regardless of these treatment steps, all films were vacuum-dried at $130{ }^{\circ} \mathrm{C}$ for $12 \mathrm{~h}$. Films were aged at ambient conditions for 290-448 days.

\section{Pure- and mixed-gas permeation}

Permeation tests were performed using automated constantvolume, variable-pressure permeation systems from Maxwell Robotics. A detailed experimental procedure for pure-gas testing is provided in the ESI. $\dagger$ For mixed-gas tests, a built-in air heating system was used to maintain the temperature at $35{ }^{\circ} \mathrm{C}$ and the gas mixture compositions in the feed and the permeate streams were measured using an Agilent 7890B gas chromatograph (GC). Aged film samples were loaded into a permeation cell in the mixed-gas system and degassed under
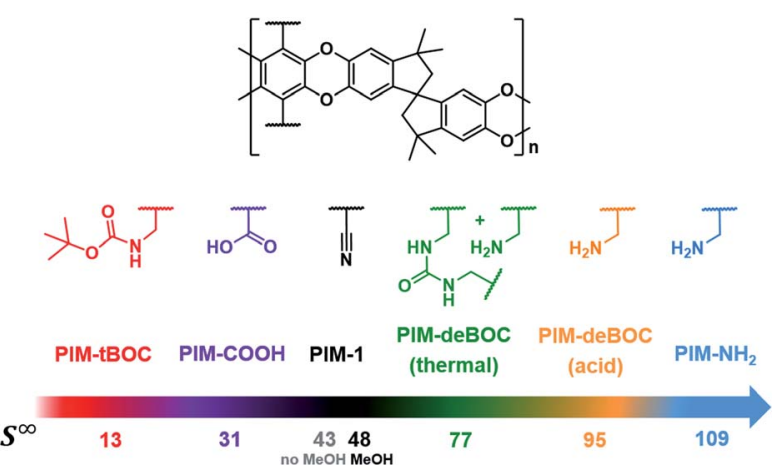

Fig. 1 Generalized PIM-1 backbone and functionalities for the six PIM1 analogues investigated in this study, along with their corresponding sorption coefficients at infinite dilution $\left(S^{\infty}\right)$ in $\mathrm{cm}_{\mathrm{STP}}{ }^{3} \mathrm{~cm}_{\text {pol }}{ }^{-3} \mathrm{~atm}^{-1}$. 
vacuum for at least $8 \mathrm{~h}$. The feed mixtures were generated at the desired composition using Bronkhorst mass flow controllers, which maintained high flowrates $(300-800 \mathrm{sccm})$ to avoid concentration polarization. A stage cut of $<0.1 \%$ was used for all tests, as recommended elsewhere. ${ }^{\mathbf{4 9}, 50}$ The upstream pressure was set using a proportional-integral-derivative (PID) controller. Steady state was verified by confirming linearity in downstream pressure rise as a function of time for the mixture and evaluation of the permeate composition over time for multiple time points. The duration of the equilibration step for each mixed-gas test was determined to be at least 10 times the pure-gas time lags of the slower permeating species (i.e., $\mathrm{CH}_{4}$ or $\mathrm{N}_{2}$ ) calculated at $1 \mathrm{~atm}$ and $35{ }^{\circ} \mathrm{C}$. At steady state, the permeating mixture was collected into a degassed volume under static vacuum, after which, gas was injected into the GC for analysis. For a typical experiment, pure-gas $\mathrm{CH}_{4}$ and $\mathrm{CO}_{2}$ permeability were first analyzed in the mixed-gas system at $1 \mathrm{~atm}$. Next, nine $\mathrm{CO}_{2} / \mathrm{CH}_{4}$ mixture compositions, defined throughout the manuscript by mole percentage, were sequentially tested for $\mathrm{CO}_{2} / \mathrm{CH}_{4}$ compositions of 10/90, 20/80, 30/70, 40/60, 50/50, 60/ 40, 70/30, 80/20, and 90/10. High performing samples were also tested using pure $\mathrm{H}_{2}$ and $\mathrm{N}_{2}$, and 50/50 mixtures of $\mathrm{H}_{2} / \mathrm{CH}_{4}$, $\mathrm{H}_{2} / \mathrm{N}_{2}$, and $\mathrm{CO}_{2} / \mathrm{N}_{2}$ at a total pressure of 2 atm. Following these low-pressure tests, the $\mathrm{CO}_{2} / \mathrm{CH}_{4}$ feed composition was fixed at $50 / 50$ and the total mixed-gas pressure was increased from 2 to 26 atm.

For $\mathrm{CO}_{2}$ pressures above $1 \mathrm{~atm}$, the fugacity was calculated to account for non-ideal gas behaviour using the virial equation of state. ${ }^{51}$ The mole fraction of gas in the downstream was calculated using GC calibration curves. The following relationships were used to calculate pure-gas permeability and the mixed-gas permeability for component i of a binary mixture, respectively:

$$
\begin{gathered}
P=\frac{l V_{\mathrm{d}}}{A R T\left(p_{2}\right)} \times \frac{\mathrm{d} p_{1}}{\mathrm{~d} t} \\
P_{\mathrm{i}}=\frac{l V_{\mathrm{d}}}{A R T\left(x_{\mathrm{i}} p_{2}\right)} \times y_{\mathrm{i}} \frac{\mathrm{d} p_{1}}{\mathrm{~d} t}
\end{gathered}
$$

where $P$ is the permeability in barrer $\left(10^{-10} \mathrm{~cm}_{\mathrm{STP}}{ }^{3} \mathrm{~cm} \mathrm{~cm} \mathrm{~cm}^{-2}\right.$ $\left.\mathrm{cm}_{\mathrm{Hg}}{ }^{-1} \mathrm{~s}^{-1}\right), l$ is the film thickness, $V_{\mathrm{d}}$ is the volume in the downstream, $p_{2}$ is the average upstream pressure, $A$ is the active cross-sectional area, $R$ is the ideal gas constant, $T$ is the absolute temperature, $\mathrm{d} p_{1} / \mathrm{d} t$ is the pressure rise in the downstream minus the leak rate. For mixed-gas calculations, $y$ and $x$ are the mole fractions of gas $\mathrm{i}$ in the downstream and the upstream, respectively, and $p_{1} \ll p_{2}$, where $p_{1}<10$ Torr. Film thicknesses and treatment conditions are summarized in Table S1. $\dagger$

\section{High-pressure pure-gas sorption}

$\mathrm{CO}_{2}, \mathrm{CH}_{4}, \mathrm{~N}_{2}$, and $\mathrm{O}_{2}$ sorption isotherms for methanol treated

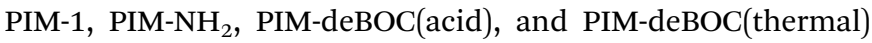
were collected at $35{ }^{\circ} \mathrm{C}$ using an automated pressure decay system from Maxwell Robotics. Detailed protocols for this test are provided in our previous work. ${ }^{52}$

Sorption in glassy polymers is commonly described through the dual-mode sorption (DMS) model: ${ }^{53,54}$

$$
C_{\mathrm{i}, \text { pure }}=k_{\mathrm{D}, \mathrm{i}} f_{i}+\frac{C_{\mathrm{H}, \mathrm{i}}^{\prime} b_{\mathrm{i}} f_{\mathrm{i}}}{1+b_{\mathrm{i}} f_{\mathrm{i}}}
$$

where $C_{\mathrm{i}}$ is the concentration of gas $\mathrm{i}$ in the polymer $\left(\mathrm{cm}_{\mathrm{STP}}{ }^{3}\right.$ $\mathrm{cm}_{\mathrm{pol}}{ }^{-3}$ ), $f_{\mathrm{i}}$ is the fugacity (atm) at equilibrium, $C_{\mathrm{H}, \mathrm{i}}^{\prime}$ is the Langmuir sorption capacity $\left(\mathrm{cm}_{\mathrm{STP}}{ }^{3} \mathrm{~cm}_{\mathrm{pol}}{ }^{-3}\right), k_{\mathrm{D}, \mathrm{i}}$ is the Henry's law constant $\left(\mathrm{cm}_{\mathrm{STP}}{ }^{3} \mathrm{~cm}_{\mathrm{pol}}{ }^{-3} \mathrm{~atm}^{-1}\right)$, and $b_{\mathrm{i}}$ is the Langmuir affinity constant $\left(\mathrm{atm}^{-1}\right) \cdot{ }^{55}$ Isotherms were fit to the DMS model via nonlinear least squares fitting by constraining $\ln \left(k_{\mathrm{D}}\right)$ versus critical temperature $\left(T_{\mathrm{c}}\right)$ to have the same slope as $\ln (S)$ versus $T_{\mathrm{c}}$ at $10 \mathrm{~atm}$, where $S$ is the sorption coefficient. ${ }^{56,57}$

Pure-gas DMS model parameters can be used to predict mixed-gas sorption as proposed by Koros. ${ }^{58,59}$ In this model, sorption into the equilibrium mode is assumed to be unaffected by competition, while co-penetrants compete to sorb into the Langmuir mode of the polymer. ${ }^{23}$ Competition for the Langmuir mode results in a depression of mixed-gas sorption for each penetrant in the mixture, which can be estimated using pure-gas DMS model parameters for penetrant i $\left(k_{\mathrm{D}, \mathrm{i}}, b_{\mathrm{i}}\right.$, and $\left.C_{\mathrm{H}, \mathrm{i}}^{\prime}\right)$ and the Langmuir affinity constant for the co-penetrant $\mathrm{j}$ in the binary mixture $\left(b_{\mathrm{j}}\right)$. The concentration of penetrant i sorbed in the polymer in the presence of a co-penetrant $\mathrm{j}$ is:

$$
C_{\mathrm{i}, \text { mixed }}=k_{\mathrm{D}, \mathrm{i}} f_{\mathrm{i}}+\frac{C_{\mathrm{H}, \mathrm{i}}^{\prime} b_{\mathrm{i}} f_{\mathrm{i}}}{1+b_{\mathrm{i}} f_{\mathrm{i}}+b_{\mathrm{j}} f_{\mathrm{j}}}
$$

where $f$ is the partial fugacity of each penetrant. Mixed-gas sorption isotherms were modeled using constrained DMS parameters. Mixed-gas fugacities were calculated by invoking the Lewis-Randall approximation. ${ }^{60}$

Pure- or mixed-gas sorption coefficients can be calculated by dividing the gas concentration by the corresponding fugacity as shown in eqn (5) and (6), respectively:

$$
\begin{gathered}
S_{\mathrm{i}, \text { pure }}=\frac{C_{\mathrm{i}}}{f_{\mathrm{i}}}=k_{\mathrm{D}, \mathrm{i}}+\frac{C_{\mathrm{H}, \mathrm{i}}^{\prime} b_{\mathrm{i}}}{1+b_{\mathrm{i}} f_{\mathrm{i}}} \\
S_{\mathrm{i}, \text { mixed }}=\frac{C_{\mathrm{i}}}{f_{\mathrm{i}}}=k_{\mathrm{D}, \mathrm{i}}+\frac{C_{\mathrm{H}, \mathrm{i}}^{\prime} b_{\mathrm{i}}}{1+b_{\mathrm{i}} f_{\mathrm{i}}+b_{\mathrm{j}} f_{\mathrm{j}}}
\end{gathered}
$$

\section{Sorption-diffusion model}

Gas transport through a polymer is often described using the sorption-diffusion model, where the permeability is defined as the product of the diffusion coefficient $\left(\mathrm{cm}^{2} \mathrm{~s}^{-1}\right)$ and the sorption coefficient $\left(\mathrm{cm}_{\mathrm{STP}}{ }^{3} \mathrm{~cm}_{\mathrm{pol}}{ }^{-3} \mathrm{~atm}^{-1}\right):{ }^{61}$

$$
P_{\mathrm{i}}=D_{\mathrm{i}} \times S_{\mathrm{i}}
$$

Pure- and mixed-gas permselectivity $(\alpha)$ is defined as the ratio of the permeabilities for pure- and mixed-gas conditions:

$$
\alpha_{\mathrm{i} / \mathrm{j}}=\frac{P_{\mathrm{i}}}{P_{\mathrm{j}}}=\frac{D_{\mathrm{i}}}{D_{\mathrm{j}}} \times \frac{S_{\mathrm{i}}}{S_{\mathrm{j}}}=\alpha_{\mathrm{D}} \times \alpha_{\mathrm{S}}
$$

where $\alpha_{\mathrm{D}}$ is the diffusion selectivity and $\alpha_{\mathrm{S}}$ is the sorption selectivity. Pure-gas sorption selectivities were estimated using best-fit curves of experimental data, while mixed-gas sorption selectivities were calculated from sorption isotherms modeled 
using constrained DMS parameters, as described earlier. Diffusion selectivities were then calculated as the ratio between pure- or mixed-gas permselectivity and sorption selectivity.

\section{Results and discussion}

In this work, mixed-gas and high-pressure transport properties of six functionalized PIMs were evaluated. As shown in Fig. 1, the PIMs investigated have identical backbones with distinct functionalities of varying $\mathrm{CO}_{2}$ affinity including the nitrile $(-\mathrm{CN})$, carboxylic acid $(-\mathrm{COOH})$, amine $\left(-\mathrm{CH}_{2} \mathrm{NH}_{2}\right)$, tert-butoxycarbonyl $\left(-\mathrm{CH}_{2} \mathrm{NHCOOC}\left(\mathrm{CH}_{3}\right)_{3}, \quad-t \mathrm{BOC}\right)$, and urea (-NHCONH-). As previously reported, PIM-deBOC(acid) and PIM-deBOC(thermal) are chemical analogues of PIM- $\mathrm{NH}_{2}$, but with distinct free volume architecture and for PIMdeBOC(thermal), a light degree of urea crosslinks. ${ }^{48}$ In our prior work, the influence of physical packing on the transport properties of these polymers were investigated under pure-gas conditions and through time-lag analysis. In this work, the influence of side-group chemistry on mixed-gas transport is probed through mixed-gas permeation and direct sorption.

In addition to mixture considerations and high-pressure, in many separation applications, PIMs will lose permeability and increase selectivity over time through a process known as physical aging, but few studies report transport performance for structural analogues that have been systematically aged. ${ }^{\mathbf{6 3 , 6 4}}$ Aging effects are also accelerated for thin films, and Jue et al. have demonstrated that industrially relevant PIM-1 hollow fibers have separation performance reminiscent of PIM-1 thick films that have aged for several years. ${ }^{\mathbf{6 5}, 66}$ To consider performance under more realistic scenarios, all films were aged for over 290 days. After aging, all films demonstrated the expected loss in permeability and increase in permselectivity typically observed for glassy polymers, ${ }^{63}$ with the exception of PIM- $t$ BOC, which had little change in permselectivity and permeability due to its low fractional free volume (Fig. S1†). ${ }^{48}$

\section{Variable composition mixed-gas permeation}

$\mathrm{CO}_{2} / \mathbf{C H}_{4}$ mixtures. Aged polymer films were first evaluated with $\mathrm{CO}_{2} / \mathrm{CH}_{4}$ binary mixed-gas feeds at a low total pressure of 2 atm (Fig. 2a and Table 1). When comparing pure- and mixed-gas tests performed at similar $\mathrm{CO}_{2}$ partial pressure of $1.2 \mathrm{~atm}$, all polymers, with the exception of PIM- $t$ BOC, display an increase in $\mathrm{CO}_{2} / \mathrm{CH}_{4}$ permselectivity and minimal changes in $\mathrm{CO}_{2}$ permeability. $\mathrm{PIM}^{-\mathrm{NH}_{2}}$ (290 d) showed an outstanding $140 \%$ increase in permselectivity from 12 in pure-gas tests to 29 in mixed-gas tests. Moreover, pure-gas permselectivities for PIM$\mathrm{NH}_{2}$ (290 d) differed between fresh (3.6) and aged (12) films, showing the effect of aging on permselectivity of these films. In mixed-gas conditions, all samples containing amine functionality (PIM-NH ${ }_{2}$, PIM-deBOC(acid), and PIM-deBOC(thermal)) exhibited nearly identical permselectivities between 25 and 29 , suggesting that mixed-gas transport is primarily controlled by competition as opposed to diffusion. However, when comparing the change in selectivity between pure-gas calculations and mixed-gas experiments, PIM-deBOC(acid) and PIM-
deBOC(thermal) exhibited a smaller increase in permselectivity of $85 \%$ and $34 \%$, respectively. Interestingly, there are significant deviations between time-lag and equilibrium sorption analysis, particularly for $\mathrm{PIM}-\mathrm{NH}_{2} \cdot{ }^{48}$ These differences are associated with non-linearities in the concentration gradient through the polymer film. ${ }^{\mathbf{4 4 , 4 6 , 6 7}}$ Thus, the smaller increase in mixed-gas permselectivity for PIM-deBOC(thermal) versus PIM$\mathrm{NH}_{2}$ is attributed to its lower Langmuir affinity for $\mathrm{CO}_{2}$, which is further discussed later. When considering other derivatives, small variations were observed between pure- and mixed-gas $\mathrm{CO}_{2} / \mathrm{CH}_{4}$ permselectivities for aged, untreated PIM-1 (+18\%) and PIM-COOH $(+26 \%)$, and aged, methanol treated PIM-1 $(+16 \%)$ and PIM- $t$ BOC $(-6 \%)$. In other studies, small but significant differences in $\mathrm{CO}_{2} / \mathrm{CH}_{4}$ mixed- and pure-gas permselectivities have been documented for glassy polymers including the 6FDA-HAB polyimide $(+25 \%)$, TDA1-APAF $(+7 \%)$, and thermally rearranged PIM-6FDA-OH $(+15 \%)$, where permselectivity increases for the mixed-gas case were also attributed to competition. ${ }^{35,50,68}$

To assess the influence of changes in $\mathrm{CO}_{2}$ content on mixedgas permeation, incremental $\mathrm{CO}_{2} / \mathrm{CH}_{4}$ mixture compositions were investigated at atal pressure of 2 atm (Fig. 2 and $\mathrm{S} 2 \dagger$ ). $\mathrm{CO}_{2}$ and $\mathrm{CH}_{4}$ permeabilities decreased with increasing $\mathrm{CO}_{2}$ composition from $10 \%$ to $90 \%$ (Fig. $2 \mathrm{~b}$ ). This trend is consistent with the decrease in sorption expected for glassy polymers with increasing pressure in the framework of the dual-mode sorption model when no significant plasticization-induced variations in diffusion are expected. ${ }^{35}$ As pressure increases and Langmuir modes saturate, the sorption coefficient, and thus permeability, decreases due to the higher energetic penalty required to sorb into the Henry's law mode. ${ }^{69,70}$ The $\mathrm{CO}_{2} / \mathrm{CH}_{4}$ mixed-gas permselectivity slightly increased with increasing content of $\mathrm{CO}_{2}$, demonstrating how competition (i.e., $\mathrm{CH}_{4}$ exclusion from the polymer matrix) is proportional to the molar ratio of $\mathrm{CO}_{2}$ over $\mathrm{CH}_{4}$ in the mixture. When comparing pure- and mixed-gas tests at the same $\mathrm{CO}_{2}$ pressure, $\mathrm{CO}_{2}$ permeabilities were roughly equivalent to each other. Conversely, mixed-gas $\mathrm{CH}_{4}$ permeability was significantly lower compared to pure-gas permeabilities ( $c f$., inset in Fig. $2 \mathrm{~b}$ and Table 1), due to competitive sorption and exclusion of $\mathrm{CH}_{4}$. As presented in Fig. S2, $\dagger$ these trends applied to every aged PIM considered except PIM- $t$ BOC, which was the polymer with the lowest $\mathrm{CO}_{2}$ infinite dilution sorption coefficient among those tested (Fig. 1). Taken together, the decrease in $\mathrm{CH}_{4}$ permeability from pure- to mixed-gas tests at the same partial pressure of $\mathrm{CH}_{4}$ correlated directly with the $\mathrm{CO}_{2}$ affinity of the polymer, as shown in Fig. S3. $\dagger$

The shape of the isobaric mixed-gas permeability trends also provides valuable insights. By increasing $\mathrm{CO}_{2}$ compositions from $10 \%$ to $90 \%, \mathrm{CO}_{2}$ permeabilities decreased by $60 \%$ for PIM-NH ${ }_{2}(290 \mathrm{~d})$ and $50 \%$ for PIM-deBOC(acid) and the magnitude of the decreases correlated well with their Langmuir affinity constants of $1.006 \mathrm{~atm}^{-1}$ and $0.895 \mathrm{~atm}^{-1}$, respectively (Table S3†). In contrast, PIM-tBOC showed a small change in permeability over the same range of $\mathrm{CO}_{2}$ compositions from 118 to 99 barrer, which was ascribed to a low $b$ value of $0.427 \mathrm{~atm}^{-1}$. In each case, tests at incremental $\mathrm{CO}_{2}$ compositions illustrate the important role of sorption on transport at varying feed 
(a)

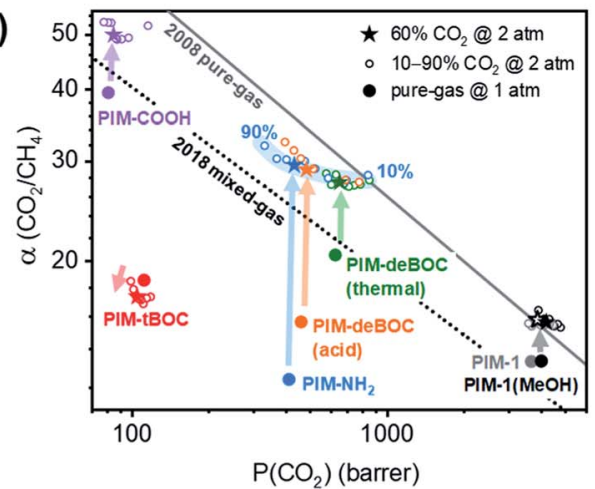

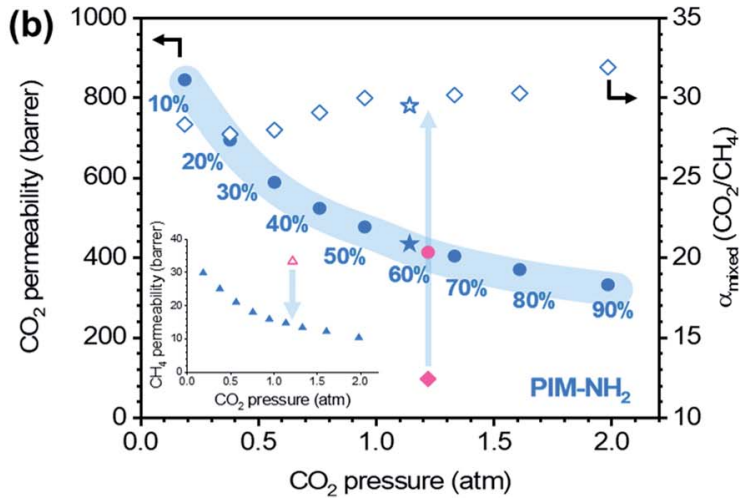

Fig. 2 (a) Robeson plot for aged PIMs containing 2008 pure-gas and 2018 mixed-gas upper-bound relationships. Pure-gas tests were performed at $35^{\circ} \mathrm{C}$ and $1.2 \mathrm{~atm}$ (filled circles) and mixed-gas tests at $35^{\circ} \mathrm{C}$ and approximately $2 \mathrm{~atm}$ at nine compositions (open circles). Stars denote mixed-gas tests performed with a $60 / 40 \mathrm{CO}_{2} / \mathrm{CH}_{4}$ composition and a $\mathrm{CO}_{2}$ partial pressure similar to that of pure-gas. (b) $\mathrm{CO}_{2}$ mixed-gas permeabilities (blue filled circles) and $\mathrm{CO}_{2} / \mathrm{CH}_{4}$ permselectivities (open diamonds) for incremental $\mathrm{CO}_{2}$ compositions at a total pressure of approximately $2 \mathrm{~atm}$ for $\mathrm{PIM}-\mathrm{NH}_{2}$. Inset corresponds to mixed-gas $\mathrm{CH}_{4}$ permeabilities (filled triangles). Pink points indicate pure-gas $\mathrm{CO}_{2}$ (circle) and $\mathrm{CH}_{4}$ (open triangle) permeabilities, and pure-gas $\mathrm{CO}_{2} / \mathrm{CH}_{4}$ permselectivity (diamond). Stars denote permselectivity (open) and $\mathrm{CO} 2$ permeability (filled) tested at a $60 / 40 \mathrm{CO}_{2} / \mathrm{CH}_{4}$ composition. For PIM-NH pressure was $1.9 \mathrm{~atm}$. At a $90 \% \mathrm{CO}_{2}$ composition, the total mixed-gas pressure was set to $2.2 \mathrm{~atm}$ to maintain a high flux and a low stage cut.

conditions. At $\mathrm{CO}_{2}$ compositions of $10 \%$, for instance, $\mathrm{PIM}-\mathrm{NH}_{2}$ has competitive performance above the 2008 upper bound, indicating its potential for low-pressure and low concentration $\mathrm{CO}_{2}$ removal applications, such as those found in biogas purification. $^{71}$

Other mixtures. Binary $\mathrm{H}_{2} / \mathrm{N}_{2}, \mathrm{H}_{2} / \mathrm{CH}_{4}$, and $\mathrm{CO}_{2} / \mathrm{N}_{2}$ mixtures were also investigated due to their relevance in commercial and emerging membrane-based applications including hydrogen purification and post-combustion carbon capture. ${ }^{72}$ For these separations, significant competitive sorption effects were also observed in PIM- $\mathrm{NH}_{2}$ (Fig. S4 $\dagger$ ) and aligned directly with critical temperatures of the gases, summarized in Table S2. $\dagger$ Notably, $\mathrm{CO}_{2} / \mathrm{N}_{2}$ mixed-gas permselectivity increased by 3.5 times $(+250 \%)$ that of the pure-gas performance, higher than the enhancement measured for $\mathrm{CO}_{2} / \mathrm{CH}_{4}$. This result is consistent with the rationale that the driving force for competition is the relative difference in sorption of two gases for a binary mixture. Critical temperature is often used as a correlating variable for sorption, ${ }^{73}$ and indeed $T_{\mathrm{c}}\left(\mathrm{N}_{2}\right)<T_{\mathrm{c}}\left(\mathrm{CH}_{4}\right) \ll T_{\mathrm{c}}\left(\mathrm{CO}_{2}\right)$. Thus, increases in $\mathrm{CO}_{2} / \mathrm{N}_{2}$ permselectivity are expected to exceed those for $\mathrm{CO}_{2} / \mathrm{CH}_{4}$. Enhancements in $\mathrm{CO}_{2} / \mathrm{N}_{2}$ permselectivity have also been reported for other PIMs, including TZ-PIM ${ }^{38}(+47 \%)$ and MTZ-PIM ${ }^{74}(+80 \%)$, but to a lesser extent than that for PIM$\mathrm{NH}_{2}$. Similar considerations apply for $\mathrm{H}_{2}$-based separations, which showed a reduction in $\mathrm{H}_{2} / \mathrm{CH}_{4}$ and $\mathrm{H}_{2} / \mathrm{N}_{2}$ permselectivity for PIM-NH $\mathrm{N}_{2}$, consistent with the stronger sorption preference of $\mathrm{CH}_{4}$ and $\mathrm{N}_{2}$ compared to $\mathrm{H}_{2}$.

Table 1 Pure- and mixed-gas permeabilities and permselectivities tested at $1.2 \mathrm{~atm}$ partial pressure of $\mathrm{CO}_{2}$ and $35{ }^{\circ} \mathrm{C}$. All uncertainties were calculated from error propagation and each test was performed on independently cast polymer films

\begin{tabular}{|c|c|c|c|c|c|c|c|c|}
\hline Polymer sample designation & $\begin{array}{l}\text { Aging time } \\
\text { (days) }\end{array}$ & Treatment after casting $^{b}$ & \multicolumn{4}{|c|}{ Permeability (barrer) } & \multicolumn{2}{|c|}{ Selectivity $(\alpha)$} \\
\hline PIM-1 (381 d) & 381 & $\mathrm{MeOH}$ & $4000 \pm 200$ & $4200 \pm 200$ & $300 \pm 20$ & $270 \pm 10$ & $13.4 \pm 0.9$ & $16 \pm 1$ \\
\hline PIM-NH ${ }_{2}(\text { fresh })^{a}$ & 1 & $\mathrm{MeOH}$ & $1070 \pm 60$ & $845 \pm 50$ & $300 \pm 15$ & $33.5 \pm 5.0$ & $3.6 \pm 0.3$ & $25.2 \pm 3.9$ \\
\hline PIM-NH ${ }_{2}(290 \mathrm{~d})^{c}$ & 290 & $\mathrm{MeOH}$ & $410 \pm 20$ & $430 \pm 20$ & $33 \pm 2$ & $14.7 \pm 0.8$ & $12 \pm 1$ & $29 \pm 2$ \\
\hline PIM- $t$ BOC & 351 & $\mathrm{MeOH}$ & $110 \pm 20$ & $100 \pm 10$ & $6.1 \pm 0.8$ & $6.1 \pm 0.8$ & $18 \pm 3$ & $17 \pm 3$ \\
\hline PIM-deBOC(acid) & 339 & $\mathrm{MeOH}$ & $460 \pm 20$ & $480 \pm 20$ & $30 \pm 1$ & $16.7 \pm 0.6$ & $15.6 \pm 0.9$ & $29 \pm 2$ \\
\hline PIM-deBOC(thermal) & 343 & $\mathrm{MeOH}$ & $630 \pm 30$ & $650 \pm 30$ & $31 \pm 2$ & $24 \pm 1$ & $20 \pm 1$ & $28 \pm 2$ \\
\hline PIM-1 (402 d) & 402 & Vacuum dry & $3700 \pm 100$ & $3900 \pm 100$ & $280 \pm 10$ & $250 \pm 10$ & $13.3 \pm 0.7$ & $15.8 \pm 0.9$ \\
\hline PIM-COOH (330 d) & 330 & Vacuum dry & $81 \pm 4$ & $90 \pm 20$ & $2.1 \pm 0.1$ & $1.7 \pm 0.1$ & $39 \pm 3$ & $50 \pm 4$ \\
\hline
\end{tabular}

${ }^{a}$ Mixed-gas tests were performed at a 1.6 atm partial pressure of $\mathrm{CO}_{2} \cdot{ }^{b}$ Treatment designations: $\mathrm{MeOH}$ (MeOH soak for $24 \mathrm{~h}$ followed by a vacuum dry at $130{ }^{\circ} \mathrm{C}$ for $12 \mathrm{~h}$ ), vacuum dry (dry at $130{ }^{\circ} \mathrm{C}$ for $12 \mathrm{~h}$ ), and $\mathrm{CO}_{2}$ conditioning (pure-gas $\mathrm{CO}_{2}$ test up to 29 atm). Sample thicknesses and treatments are summarized in Table S1. ${ }^{c}$ Differences in PIM- $\mathrm{NH}_{2}$ aging rate reflects the typical variation in permeation properties for two microporous films casted independently. 


\section{Pure-gas sorption tests and mixed-gas sorption predictions}

Pure-gas sorption isotherms for methanol treated PIM-1 and PIM- $\mathrm{NH}_{2}$ derivatives are presented in Fig. $3 \mathrm{a}$ and $\mathrm{S} 5, \dagger$ along with previously published sorption isotherms for untreated PIM-1 and PIM-COOH. ${ }^{40}$ As shown in Fig. S5a and $b, \dagger$ the relative order in $\mathrm{CO}_{2}$ uptake observed for each film at $1 \mathrm{~atm}$ (PIM- $t$ BOC $\ll$ PIM-1 < PIM-deBOC(thermal) < PIM-deBOC(acid) $\approx$ PIM- $\mathrm{NH}_{2}$ ) correlated remarkably well with the relative increase in $\mathrm{CO}_{2} / \mathrm{CH}_{4}$ mixed-gas permselectivity for each PIM. In contrast, $\mathrm{O}_{2}, \mathrm{CH}_{4}$, and $\mathrm{N}_{2}$ isotherms show a different trend in

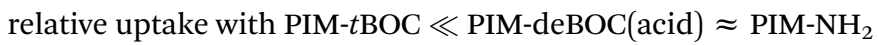
$<$ PIM-1 $\approx$ PIM-deBOC(thermal). To provide deeper physical insight into the distinct $\mathrm{CO}_{2}$ sorption behavior compared to that of other gases, the pure-gas sorption at infinite dilution $\left(S_{\infty}\right)$ was calculated. This material property, $S_{\infty}$, describes sorption of the first gas molecule into the polymer matrix and is dependent on temperature. ${ }^{\mathbf{4 0} 69}$ By taking the limit of eqn (5) as fugacity approaches zero, $S_{\infty}$ is defined as:

$$
S_{\infty}=\lim _{f \rightarrow 0} S=k_{\mathrm{D}}+C_{\mathrm{H}}^{\prime} b
$$

DMS parameters and $S_{\infty}$ values for all isotherms, including untreated PIM-COOH and PIM-1 ${ }^{40}$ are summarized in Table S3. $\dagger$ In line with the aforementioned sorption trends, the relative order of magnitude for $S_{\infty}$ and $b$ for $\mathrm{CO}_{2}$ (Fig. 1 and Table S3†) correlates with the relative increase in permeability between pure-gas and mixed-gas measurements in Fig. 2a. At the same time, the relative order of $S_{\infty}$ for $\mathrm{O}_{2}, \mathrm{~N}_{2}$, and $\mathrm{CH}_{4}$, aligns with the respective uptake trends of these gases, indicating a strong chemical interaction for PIM- $\mathrm{NH}_{2}$ and $\mathrm{CO}_{2}$ that is not observed for gases with lower critical temperatures.

The effect of competitive sorption was modeled from puregas isotherms using eqn (6), as presented in Fig. 3a and S6. $\dagger$ This modeling approach has demonstrated good agreement with experimental mixed-gas sorption for PIM-1, TZ-PIM, PTMSP, 6FDA-HAB and its TR450 analogue, 6FDA-mPDA, CTA, and PMMA. ${ }^{19,21,23,24,29,51,75}$ Thermodynamically rigorous models such as the nonequilibrium lattice fluid (NELF) ${ }^{76}$ model would provide more robust mixed-gas predictions, ${ }^{23,77}$ but lattice fluid parameters (i.e., $\rho^{*}, T^{*}, p^{*}$ ) cannot be directly determined for the PIMs studied in this work because the polymers degrade below their glass transition temperature..$^{78,79}$ As shown in Fig. S6a, $\uparrow$ experimental pure-gas and predicted 50/ $50 \mathrm{CO}_{2} / \mathrm{CH}_{4}$ mixed-gas PIM-1 sorption isotherms obtained in this work aligned very well with experimental results reported by Vopička et al. ${ }^{\mathbf{8 0}}$ The modeling approach was thus extended to all six PIMs, as presented in Fig. S6 and S7. $\dagger$ Predicted mixedgas sorption isotherms showed a small decrease in $\mathrm{CO}_{2}$ uptake ranging between $-5 \%$ and $-9 \%$ for all films, while $\mathrm{CH}_{4}$
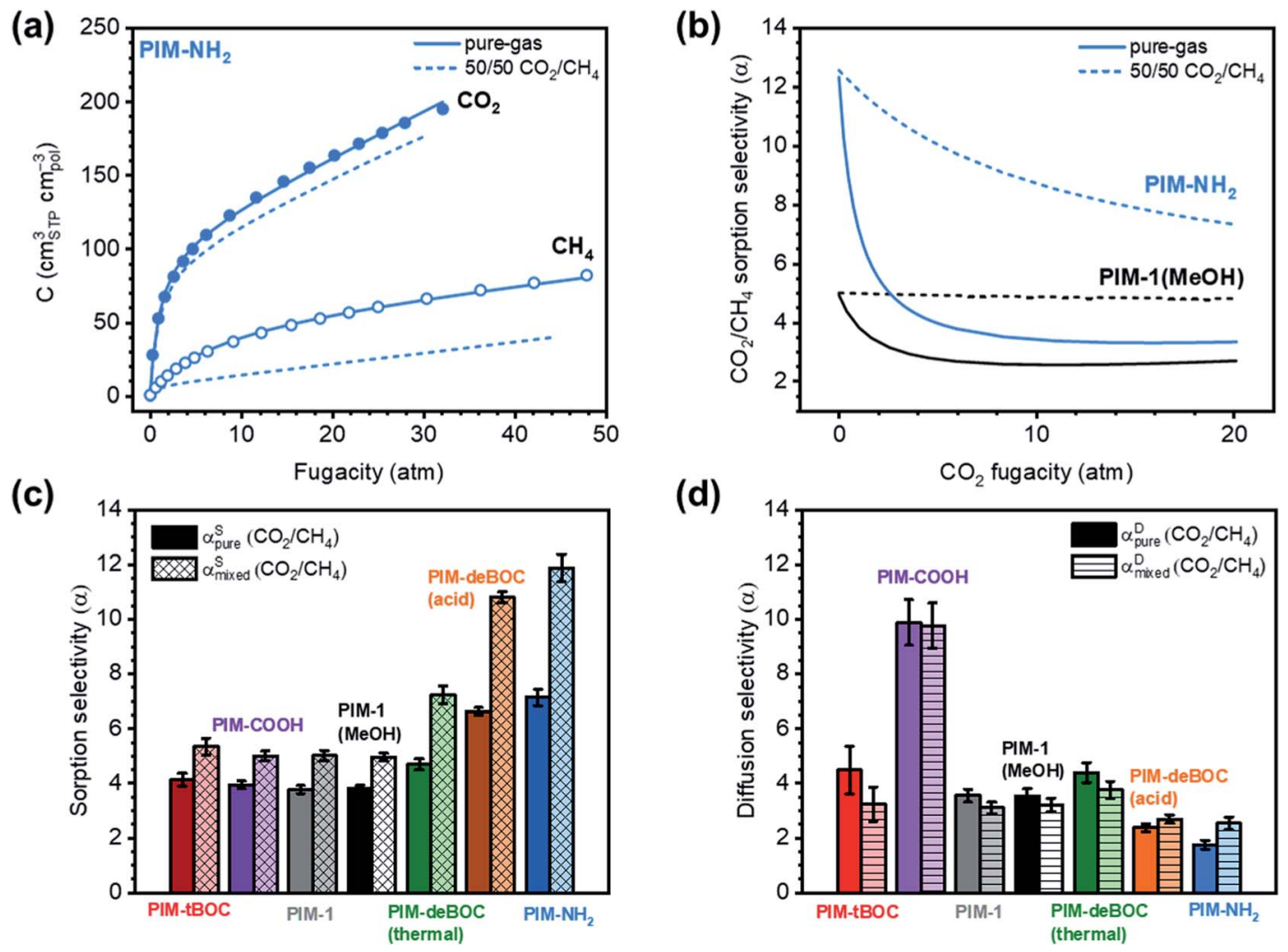

Fig. 3 (a) Pure-gas $\mathrm{CO}_{2}$ and $\mathrm{CH}_{4}$ sorption isotherms (circles) fitted with the $\mathrm{DMS}$ model (solid lines), and $\mathrm{CO}_{2}$ and $\mathrm{CH}_{4} 50 / 50$ mixed-gas sorption isotherms predicted with the DMS model (dashed lines) for PIM- $\mathrm{NH}_{2}$. Open $\left(\mathrm{CH}_{4}\right)$ and filled $\left(\mathrm{CO}_{2}\right)$ symbols denote experimentally collected data. (b) Pure-gas $\mathrm{CO}_{2}$ and $\mathrm{CH}_{4}$ sorption selectivities (solid lines) and predicted $50 / 50 \mathrm{CO}_{2} / \mathrm{CH}_{4}$ sorption selectivities (dashed lines) for PIM-NH . (c) Pure- and predicted mixed-gas sorption selectivities at a $\mathrm{CO}_{2}$ partial fugacity of $1 \mathrm{~atm}$. (d) Pure- and mixed-gas diffusion selectivities calculated using the sorption-diffusion model at a $\mathrm{CO}_{2}$ partial fugacity of $1 \mathrm{~atm}$. 
isotherms displayed a much more pronounced decrease ranging from $-29 \%$ to $-47 \%$. Because of its high solubility, $\mathrm{CO}_{2}$ sorption is weakly affected by the presence of $\mathrm{CH}_{4}$ in the mixture while $\mathrm{CH}_{4}$ experiences a significant reduction in sorption, resulting in a beneficial increase in $\mathrm{CO}_{2} / \mathrm{CH}_{4}$ sorption selectivity (Fig. S7b and $\mathrm{c} \dagger$ ). The effects of competition for increasing fugacities can be visualized by plotting the pure- and mixed-gas $\quad \mathrm{CO}_{2} / \mathrm{CH}_{4}$ sorption selectivities $\left(\alpha_{\text {pure }}^{\mathrm{S}}\right.$ and $\alpha_{\text {mixed }}^{\mathrm{s}}$ ) (Fig. $3 \mathrm{~b}$ and $\mathrm{S} 7 \dagger$ ). As shown in Fig. $3 \mathrm{~b}, \alpha_{\text {mixed }}^{\mathrm{s}}$ for PIM-1 and $\mathrm{PIM}-\mathrm{NH}_{2}$ is consistently higher than $\alpha_{\text {pure }}^{\mathrm{S}}$ for all fugacities considered.

Diffusion selectivity was also evaluated. To this end, pureand mixed-gas diffusion selectivities $\left(\alpha_{\text {pure }}^{\mathrm{D}}\right.$ and $\left.\alpha_{\text {mixed }}^{\mathrm{D}}\right)$ were estimated via the sorption-diffusion model (eqn (7)) using experimental pure-gas and modeled mixed-gas sorption coefficients for a $\mathrm{CO}_{2}$ partial fugacity of $1 \mathrm{~atm}$. As shown in Fig. 3d and Table $\mathrm{S} 4, \dagger$ there is little change between the $\alpha_{\text {pure }}^{\mathrm{D}}$ and $\alpha_{\text {mixed }}^{\mathrm{D}}$ for each sample, reinforcing our assertion that the increase in mixed-gas permselectivity is driven by competition.

\section{Pure-gas and mixed-gas plasticization}

Penetrant-induced plasticization is a significant challenge for the deployment of membranes for natural gas purification. ${ }^{\mathbf{8 1}} \mathrm{At}$ industrially relevant pressures, penetrants like $\mathrm{CO}_{2}$ can swell the polymer and result in detrimental losses in selectivity. Effective methods to mitigate plasticization involve increasing interchain rigidity with addition of strong secondary interactions, ${ }^{\mathbf{8}, 82-84}$ thermal annealing, ${ }^{\mathbf{8 5}-87}$ or chemical crosslinking. ${ }^{\mathbf{8 8 , 8 9}}$ Here, we investigate the influence of amine hydrogen bonding and $-t$ BOC functionality on $\mathrm{CO}_{2}$-induced plasticization of PIM$\mathrm{NH}_{2}$ derivatives. As shown in Fig. 4a, PIM-1 showed a pure-gas plasticization pressure at a fugacity of 14 atm while PIM-NH PIM-deBOC(acid), and PIM-deBOC(thermal) showed no plasticization pressure up to a feed fugacity of $29 \mathrm{~atm}$. The shape of the high-pressure curves for the $\mathrm{PIM}^{-\mathrm{NH}_{2}}$ derivatives; in particular, the significant drop in permeability at low fugacity, is associated with the strong contribution to Langmuir mode sorption, as can be gleaned from Fig. 3a and S6. $\uparrow$ In contrast, PIM- $t$ BOC exhibited a plasticization pressure at a fugacity of 10 atm, which was ascribed to weaker interchain interactions between $-t$ BOC groups compared to dipolar $-\mathrm{CN}$ groups and hydrogen bonding $-\mathrm{NH}_{2}$ groups.

PIM- $\mathrm{NH}_{2}$ was further evaluated for plasticization stability using a 50/50 $\mathrm{CO}_{2} / \mathrm{CH}_{4}$ mixture up to total feed fugacity of 24 atm (Fig. 4). Mixed-gas tests up to total fugacity of 5 atm were also provided for the other derivatives in Fig. S8 and S9. $\uparrow$ For all PIM- $\mathrm{NH}_{2}$ films, the $\mathrm{CO}_{2} / \mathrm{CH}_{4}$ mixed-gas permselectivity increased slightly up to a total fugacity of 5 atm as shown in Fig. 4b and S9a. $\uparrow$ This unusual finding relates to a favorable combination of $\mathrm{CO}_{2} / \mathrm{CH}_{4}$ competitive effects and high $\mathrm{CO}_{2}-$ polymer affinity. Pure-gas tests up to 2.5 atm at similar partial fugacity were also compared to the mixed-gas plasticization curves in Fig. 4c, $\mathrm{S} 10$ and $\mathrm{S} 11 . \dagger$ In each case, $\mathrm{CO}_{2}$ permeability is essentially the same in pure- and mixed-gas scenarios, while $\mathrm{CH}_{4}$ mixed-gas permeabilities decrease significantly compared to pure-gas values, a clear demonstration of competitive sorption in $\mathrm{CO}_{2}$-containing mixtures. $\mathrm{CO}_{2} / \mathrm{CH}_{4}$ mixed-gas plasticization was further evaluated by inspecting the copermeability of $\mathrm{CH}_{4}$ with the mixture, an unambiguous indicator of plasticization. ${ }^{34}$ Since $\mathrm{CH}_{4}$ is not a typical plasticizing gas, its pure-gas permeability is only expected to decrease with increasing fugacity. However, when co-permeating with $\mathrm{CO}_{2}$, $\mathrm{CH}_{4}$ diffusion is expected to increase more readily by $\mathrm{CO}_{2}$ induced plasticization, resulting in an accentuated plasticization pressure curve for $\mathrm{CH}_{4} \cdot{ }^{23}$ As presented in Fig. 4d, S10 and S11, $\uparrow$ PIM-1 shows an immediate up-turn in $\mathrm{CH}_{4}$ permeability with increasing fugacity, while $\mathrm{PIM}-\mathrm{NH}_{2}$ retains stable $\mathrm{CH}_{4}$ permeability that follows trends expected for non-plasticized glassy polymers up to a total feed fugacity of $24 \mathrm{~atm}$. Moreover, by increasing $\mathrm{CO}_{2}$ partial pressure from 2 atm to 10 atm, there is a decrease in mixed-gas selectivity for both treated $(-36 \%)$ and untreated $(-32 \%)$ PIM-1 that is significantly more pronounced than that of $\mathrm{PIM}^{-\mathrm{NH}_{2}}(-10 \%)$, as shown on the Robeson plot in Fig. $4 \mathrm{~b}$.

\section{Comparisons to other microporous polymers}

Mixed-gas analysis at low pressures demonstrated how functionality influences competitive sorption for PIMs. To contextualize these findings, a literature survey of $\mathrm{CO}_{2} / \mathrm{CH}_{4}$ pure- and mixed-gas data for microporous polymers is summarized in Table S5 $\dagger$ and Fig. 5. For the comparison shown in Fig. 5a, only literature studies reporting (1) pure-gas permeability measured at a pressure consistent with the $\mathrm{CO}_{2}$ partial pressure reported for the mixed-gas test, and (2) $\mathrm{CO}_{2}$ and $\mathrm{CH}_{4}$ high-pressure sorption isotherms were included. The ratio of $\mathrm{CO}_{2} / \mathrm{CH}_{4}$ mixed- to pure-gas permselectivity $\left(\alpha_{\text {mixed }} / \alpha_{\text {pure }}\right)$ was plotted against $\alpha_{\text {pure }}^{\mathrm{S}}$, where $\alpha_{\text {pure }}^{\mathrm{D}}$ and $\alpha_{\text {mixed }}^{\mathrm{D}}$ were assumed invariant at low $\mathrm{CO}_{2}$ partial pressures, consistent with our findings presented in Fig. 3d. As a general trend, as $\alpha_{\text {pure }}^{\mathrm{s}}$ increases, $\alpha_{\text {mixed }} /$ $\alpha_{\text {pure }}$ increases largely due to competitive sorption effects. Similarly, at a total pressure of 2 atm, the six PIM derivatives show an increasing trend, where amine-functionalized PIM$\mathrm{NH}_{2}$ and its chemical analogue, PIM-deBOC(acid), show the largest increase in $\alpha_{\text {mixed }} / \alpha_{\text {pure }}$ and the highest $\alpha_{\text {pure }}^{\mathrm{s}}$. The chemical structures of polymers showcased in Fig. 5a are shown in Fig. S12 $\uparrow$ in order of increasing $\alpha_{\text {pure }}^{\mathrm{s}}$ values. Among the samples considered, backbones containing $-\mathrm{OH}^{34,83}$ and - $\mathrm{COOH}^{\mathbf{9 0 , 9 1}}$ groups show generally higher $\mathrm{CO}_{2} / \mathrm{CH}_{4} \alpha_{\text {pure values }}^{\mathrm{S}}$ than backbones containing groups such as $-\mathrm{F},-\mathrm{H}$, or -CN. ${ }^{17,22,34,91-96}$ Moreover, all polymers considered from the literature have $\alpha_{\text {pure }}^{\mathrm{S}}$ below 5.5 and a $\alpha_{\text {mixed }} / \alpha_{\text {pure }}$ less than 1.5. In contrast, PIM-NH $\mathrm{N}_{2}$ (2.4) and PIM-deBOC(acid) (1.9) showed the highest improvements to $\mathrm{CO}_{2} / \mathrm{CH}_{4} \alpha_{\text {mixed }}$ (Fig. 5a). To the best of our knowledge, these improvements represent a record for microporous polymer membranes, highlighting the intriguing benefits of using amine-functionalized microporous polymers for $\mathrm{CO}_{2}$-based separations. Other amine-containing PIMs such as TZ-PIM and AO-PIM have shown less pronounced changes in sorption selectivity, as presented in the sorption upper bound in Fig. S13. $\dagger$ These trends correlate with lower $\mathrm{CO}_{2}$ Langmuir affinities for TZ-PIM-1 $\left(b=0.437 \mathrm{~atm}^{-1}\right)$ and AO-PIM-1 $(b=$ $\left.0.324 \mathrm{~atm}^{-1}\right)$ than PIM-NH${ }_{2}\left(b=1.006 \mathrm{~atm}^{-1}\right) .{ }^{20}$ In these cases, 

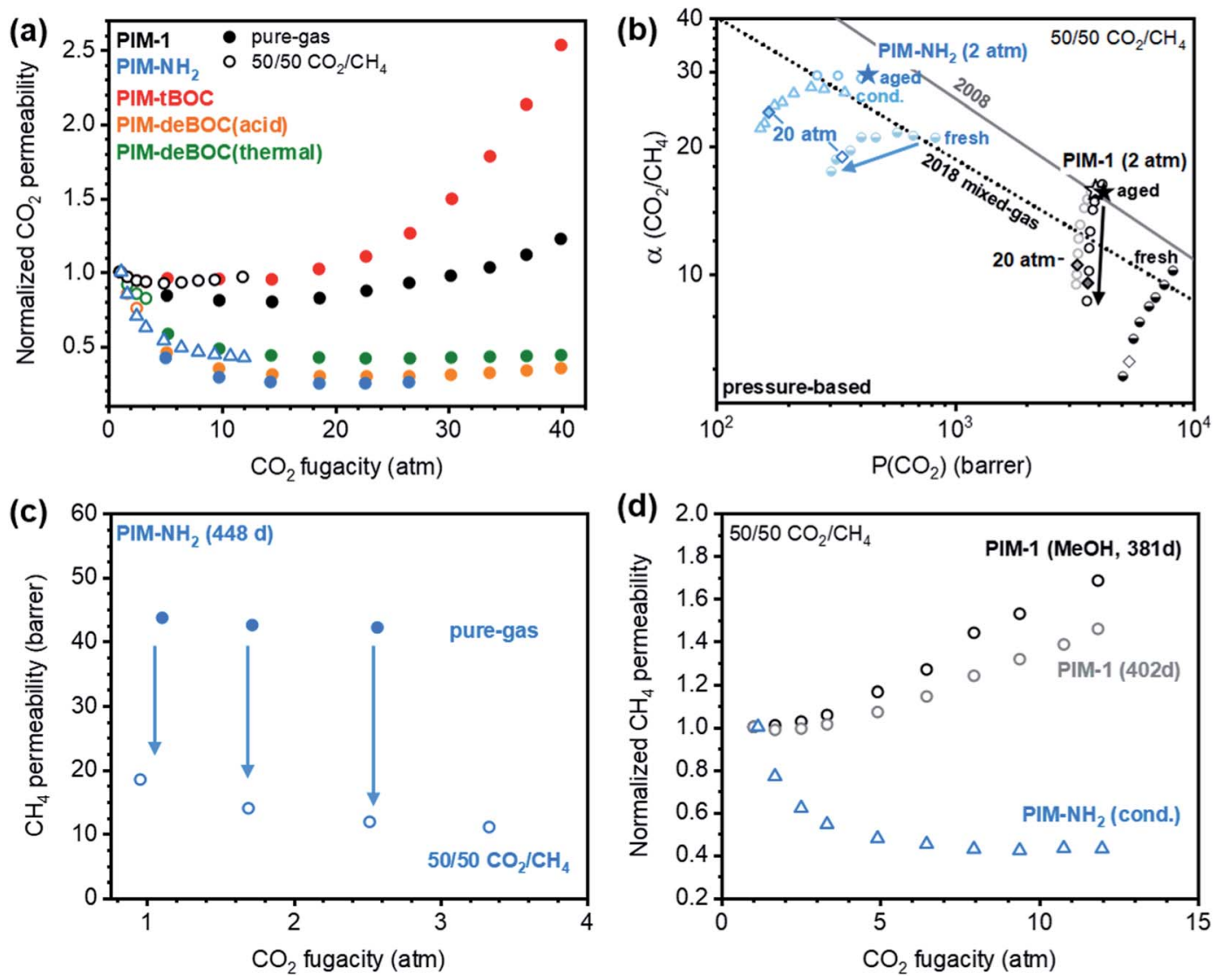

Fig. 4 (a) Pure- (filled circles) and mixed-gas (open shapes) normalized $\mathrm{CO}_{2}$ permeabilities for PIM films. (b) $\mathrm{Mixed}-\mathrm{gas} \mathrm{CO}_{2} / \mathrm{CH}_{4}$ upper-bound and plasticization performance for conditioned PIM- $\mathrm{NH}_{2}$ (open blue triangles), fresh PIM- $\mathrm{NH}_{2}$ (half-filled blue circles), aged PIM-1 films which underwent methanol treatment (381 d, open black circles) or no methanol treatment (402 d, open gray circles), and a freshly methanol-treated PIM-1 film (half-filled black circles). Mixed-gas tests performed with a $60 / 40 \mathrm{CO}_{2} / \mathrm{CH}_{4}$ mixture at 2 atm total pressure are denoted as stars. Highpressure mixed-gas points collected at a total pressure of $20 \mathrm{~atm}$ (e.g., $10 \mathrm{~atm}$ of $\mathrm{CO}_{2}$ ) are highlighted as diamonds for comparison with the pressure-based 2018 mixed-gas upper bound. Permeability data in this plot was specifically calculated using pressure for ease of comparison with literature. (c) Pure- and mixed-gas $\mathrm{CH}_{4}$ permeability for aged PIM- $\mathrm{NH}_{2}\left(448 \mathrm{~d}\right.$ ) up to a total pressure of 7 atm. (d) $\mathrm{Normalized} \mathrm{mixed-gas} \mathrm{CH}_{4}$ permeability versus $\mathrm{CO}_{2}$ partial pressure for methanol treated PIM-1 (open black circles), untreated PIM-1 (open gray circles), and conditioned $\mathrm{PIM}-\mathrm{NH}_{2}$ (open blue triangles). Reference data for $\mathrm{PIM}-\mathrm{NH}_{2}$ (fresh) is provided in Fig. S10. $\dagger$

we hypothesize that the lower $\mathrm{CO}_{2}$-polymer affinity may be associated with the nature of the acid-base interactions for each functional group as well as group accessibility. For instance, the amine in AO-PIM is accompanied by an -OH group that can hydrogen bond while TZ-PIM has low $\mathrm{p} K_{\mathrm{a}}$ values compared to primary amines ${ }^{38,97}$ and an aromatic ring that can create steric hindrance.

Compared to other PIM-1 analogues, the $\mathrm{CO}_{2} / \mathrm{CH}_{4}$ pure- and mixed-gas sorption selectivities for $\mathrm{PIM}-\mathrm{NH}_{2}$ are remarkably high. When considering sorption at infinite dilution, $\mathrm{PIM}-\mathrm{NH}_{2}$ falls on the infinite-dilution sorption upper bound (Fig. S13†), which was developed theoretically in 2014 by Lipscomb et al. for pure gases (i.e., excluding competitive sorption effects). As indicated by the authors, this upper bound is limited by the highest value of cohesive energy achievable in polymers, indicating that $\mathrm{PIM}-\mathrm{NH}_{2}$ sorption values fall close to this thermodynamic limit, enabling the remarkable increase in $\mathrm{CO}_{2} / \mathrm{CH}_{4}$ and $\mathrm{CO}_{2} / \mathrm{N}_{2}$ mixed-gas permselectivity compared to pure-gas results. These results suggest a unique interaction between the Lewis basic $-\mathrm{NH}_{2}$ and $\mathrm{CO}_{2}$, consistent with the outstanding $\mathrm{CO}_{2}$ adsorption behavior reported for amine-functionalized MOFs and amine-functionalized polysulfone..$^{37,98-101}$

Fig. $5 \mathrm{~b}$ presents a larger collection of $\alpha_{\text {mixed }} / \alpha_{\text {pure }}$ data reported for microporous polymers against pure-gas $\mathrm{CO}_{2}$ permeability, including studies that did not test sorption. For polymers reported in the literature, the $\alpha_{\text {mixed }} / \alpha_{\text {pure }}$ permselectivity ratio centers around $1 \pm 0.2$ with the lowest and highest literature values of 0.52 and 1.59 for PIM-EA( $\left(\mathrm{Me}_{2}\right)-\mathrm{TB}^{102}$ and 6FDA-DAM : DABA $(1: 2),{ }^{90}$ respectively. Remarkably, the value of $\alpha_{\text {mixed }} / \alpha_{\text {pure }}$ for PIM-NH P $_{2}(290 \mathrm{~d}$ and $448 \mathrm{~d}$ ) is 2.4, surpassing all other microporous polymers considered in the literature. Interestingly, as total pressure rises, $\alpha_{\text {mixed }} / \alpha_{\text {pure }}$ for PIM- $\mathrm{NH}_{2}$ further increases to over 3.5 at a pressure of 5.1 atm (Fig. 5a). These results demonstrate the promise of $-\mathrm{NH}_{2}$ chemistry for enhancing $\mathrm{CO}_{2}$-based mixed-gas transport through competition, while simultaneously providing plasticization resistance through hydrogen bonding. 
(a)

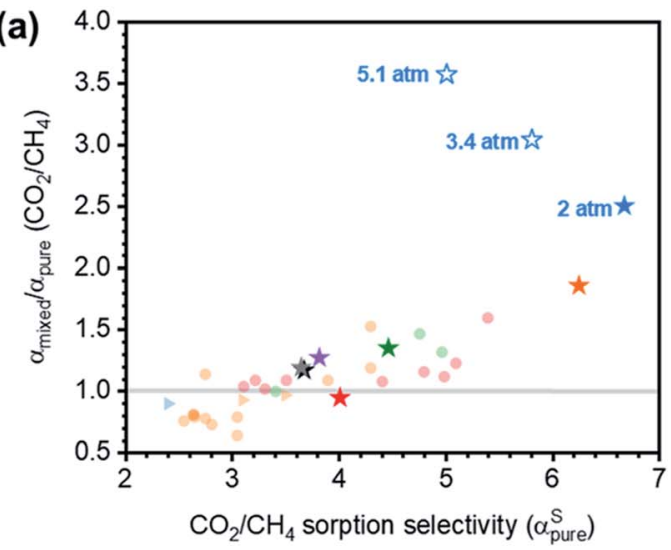

This work:

$\mathrm{P}_{\text {tot }}=2 \mathrm{~atm}, 60 / 40 \mathrm{CO}_{2} / \mathrm{CH}_{4}$

$\star$ PIM-deBOC(acid)

$\star$ PIM-deBOC(thermal)

$\star$ PIM-tBOC

$\star \mathrm{PIM}-\mathrm{COOH}$

$\star \mathrm{PIM}-1$ (MeOH)

$\star$ PIM-1

$\star$ PIM-NH

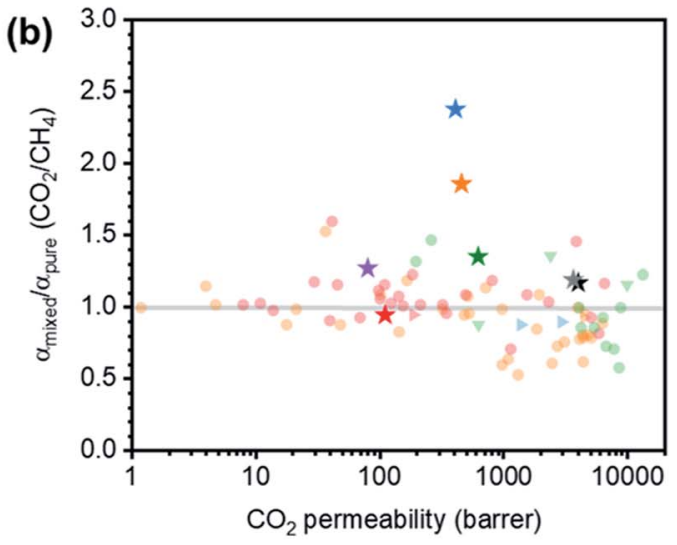

Literature:

1) $\mathrm{P}_{\text {tot }} \approx 3 \mathrm{~atm}, 65 / 35 \mathrm{CO}_{2} / \mathrm{CH}_{4}$

$\mathrm{P}_{\text {tot }} \approx 6.8 \mathrm{~atm}, 65 / 35 \mathrm{CO}_{2} / \mathrm{CH}_{4}$

$\mathrm{P}_{\text {tot }} \approx 6.8 \mathrm{~atm}, 5050 \mathrm{CO}_{2} / \mathrm{CH}_{4}$

1) $\mathrm{P}_{\text {tot }} \approx 5 \mathrm{~atm}, 65 / 35 \mathrm{CO}_{2} / \mathrm{CH}_{4}$

- $\mathrm{P}_{\text {tot }} \approx 4 \mathrm{~atm}, 50 / 50 \mathrm{CO}_{2} / \mathrm{CH}_{4}$

$\nabla \mathrm{P}_{\text {tot }} \approx 2 \mathrm{~atm}, 65 / 35 \mathrm{CO}_{2} / \mathrm{CH}_{4}$

- $\mathrm{P}_{\text {tot }} \approx 2 \mathrm{~atm}, 50 / 50 \mathrm{CO}_{2} / \mathrm{CH}_{4}$

Fig. 5 Ratio of mixed-gas and pure-gas $\mathrm{CO}_{2} / \mathrm{CH}_{4}$ permselectivity $\left(\alpha_{\text {mixed }} / \alpha_{\text {pure }}\right)$ versus (a) pure-gas $\mathrm{CO}_{2} / \mathrm{CH}_{4}$ sorption selectivity $\left(\alpha_{\text {pure }}\right)$ for aged PIMs and literature samples. All filled stars indicate tests at a mixed-gas total pressure of $2 \mathrm{~atm}$. Open blue stars indicate mixed-gas tests performed on PIM- $\mathrm{NH}_{2}$ (448 d) at $\mathrm{CO}_{2}$ total pressures of $3.4 \mathrm{~atm}$ and $5.1 \mathrm{~atm}$. (b) $\mathrm{CO}_{2}$ pure-gas permeability for this work (star symbols) and literature data (other symbols) for microporous polymers tested at approximate total pressures indicated in the legend. Detailed references, permeation data, and exact testing pressures are reported in Table S5. $\dagger$

\section{Conclusion}

Mixed-gas transport properties of six functionalized PIM-1 variants were systematically investigated after aging to study the role of $\mathrm{CO}_{2}$ affinity and polymer chemistry on competitive sorption. Low-pressure mixed-gas tests revealed a relationship between $\mathrm{CO}_{2}$ sorption affinity and changes in permselectivities of mixed-gas tests compared to pure-gas tests. Aminefunctionalized PIM-1 showed a $140 \%$ increase in mixed-gas $\mathrm{CO}_{2} / \mathrm{CH}_{4}$ selectivity and a $250 \%$ increase in $\mathrm{CO}_{2} / \mathrm{N}_{2}$ mixed-gas selectivity compared to pure-gas results performed at the same partial pressure of $\mathrm{CO}_{2}$. Mixed-gas sorption predictions and sorption-diffusion model analysis indicated that $\mathrm{CO}_{2} / \mathrm{CH}_{4}$ permselectivity improvements resulted from sorption selectivity increases that are exclusive to mixed-gas conditions. Structureproperty relationships were derived by comparing pure-gas sorption and mixed-gas permeation performance for samples in this study and for microporous polymers in the literature. PIM- $\mathrm{NH}_{2}$ showed the highest $\mathrm{CO}_{2} / \mathrm{CH}_{4}$ sorption selectivity for all polymers considered, and correspondingly, the greatest improvement for mixed-gas tests relative to pure-gas data. Microporous polymers containing hydroxyl and carboxylic acid functionalized backbones showed more limited improvements, and PIMs without hydrogen bonding moieties showed the most limited improvements. Notably, $\mathrm{PIM}^{-\mathrm{NH}_{2}}$ and its chemical analogue (PIM-deBOC(acid)) approached the theoretical sorption limit predicted in the 2014 pure-gas sorption upper bound. Finally, high-pressure $50 / 50 \mathrm{CO}_{2} / \mathrm{CH}_{4}$ mixed-gas tests revealed exceptional plasticization resistance for PIM- $\mathrm{NH}_{2}$. This effect was attributed to enhanced interchain rigidity induced by hydrogen bonding in $\mathrm{PIM}-\mathrm{NH}_{2}$. Our results demonstrate that increasing solubility-selectivity is of paramount importance to leverage competitive sorption and improve permselectivity for $\mathrm{CO}_{2}$-based gas pairs. Furthermore, plasticization resistance is necessary to retain this advantage at high pressures. Among the six PIMs considered, the primary amine functionalization (PIM$\mathrm{NH}_{2}$ ) was identified as the best compromise of these two features, displaying attractive performance under testing conditions reminiscent to those found in industry.

\section{Author contributions}

K. Mizrahi Rodriguez: conceptualization, formal analysis, methodology, investigation, data curation, visualization, writing - original draft. F. M. Benedetti: conceptualization, formal analysis, methodology, investigation, writing - review \& editing. N. Roy: investigation, data curation, writing - review \& editing. A. X. Wu: writing - review \& editing. Z. P. Smith: supervision, writing - review \& editing.

\section{Conflicts of interest}

There are no conflicts to declare.

\section{Acknowledgements}

This work was supported by the U.S. Department of Energy, Office of Science, Office of Basic Energy Sciences, Separation 
Science program under Award Number DE-SC0019087. Additionally, support to investigate low-pressure competitive sorption was provided by the Office of Naval Research (ONR) under Award Number N00014-21-1-2666 and N00014-20-1-2418. F. M. Benedetti and K. Mizrahi Rodriguez acknowledge support from the Exxon Mobil Research and Engineering Company through the MIT Energy Initiative. K. Mizrahi Rodriguez and A. X. Wu were supported by NSF-GRFP fellowships (DGE-1745302 and DGE-1122374, respectively). The authors would like to thank Taigyu Joo and Wan-Ni Wu for providing the fresh $\mathrm{PIM}-\mathrm{NH}_{2}$ and PIM-1 films used in this work, respectively. The authors also gratefully acknowledge Sharon Lin, Kayla R. Storme, Aristotle Grosz, and Duha Syar, for helping with the collection of pureand mixed-gas literature data for microporous polymers, which is considered in the comparisons performed in this work.

\section{References}

1 U.S. EIA, U.S. Natural Gas Total Consumption (Million Cubic Feet), http:/www.eia.gov/dnav/ng/hist/n9140us2a.htm, accessed 12 April 2021.

2 D. S. Sholl and R. P. Lively, Nature, 2016, 532, 435-437.

3 DOE-EPSA, Energy CO2 Emissions Impacts of Clean Energy Technology Innovation and Policy, 2017, p. 43.

4 R. W. Baker, Ind. Eng. Chem. Res., 2002, 41, 1393-1411.

5 L. M. Robeson, J. Membr. Sci., 1991, 62, 165-185.

6 N. B. Mc Keown and P. M. Budd, Chem. Soc. Rev., 2006, 35, 675-683.

7 H. B. Park, C. H. Jung, Y. M. Lee, A. J. Hill, S. J. Pas, S. T. Mudie, E. Van Wagner, B. D. Freeman and D. J. Cookson, Science, 2007, 318, 254-258.

8 Y. He, F. M. Benedetti, S. Lin, C. Liu, Y. Zhao, H. Z. Ye, T. Van Voorhis, M. G. De Angelis, T. M. Swager and Z. P. Smith, Adv. Mater., 2019, 31, 1807871.

9 H. W. H. Lai, Y. C. Teo and Y. Xia, ACS Macro Lett., 2017, 6, 1357-1361.

10 B. Comesaña-Gándara, J. Chen, C. G. Bezzu, M. Carta, I. Rose, M. C. Ferrari, E. Esposito, A. Fuoco, J. C. Jansen and N. B. McKeown, Energy Environ. Sci., 2019, 12, 27332740 .

11 R. Swaidan, B. Ghanem and I. Pinnau, ACS Macro Lett., 2015, 4, 947-951.

12 Y. Wang, X. Ma, B. S. Ghanem, F. Alghunaimi, I. Pinnau and Y. Han, Mater. Today Nano, 2018, 3, 69-95.

13 P. M. Budd, N. B. McKeown and D. Fritsch, J. Mater. Chem., 2005, 15, 1977-1986.

14 P. M. Budd, S. M. Makhseed, B. S. Ghanem, K. J. Msayib, C. E. Tattershall and N. B. McKeown, Mater. Today, 2004, 7, 40-46.

15 T. Corrado and R. Guo, Mol. Syst. Des. Eng., 2020, 5, 22-48. 16 S. Luo, Q. Zhang, L. Zhu, H. Lin, B. A. Kazanowska, C. M. Doherty, A. J. Hill, P. Gao and R. Guo, Chem. Mater., 2018, 30, 5322-5332.

17 R. Swaidan, B. Ghanem, M. Al-Saeedi, E. Litwiller and I. Pinnau, Macromolecules, 2014, 47, 7453-7462.

18 R. Swaidan, M. Al-Saeedi, B. Ghanem, E. Litwiller and I. Pinnau, Macromolecules, 2014, 47, 5104-5114.
19 E. Ricci, A. E. Gemeda, N. Du, N. Li, M. G. De Angelis, M. D. Guiver and G. C. Sarti, J. Membr. Sci., 2019, 585, 136-149.

20 A. E. Gemeda, Solubility, diffusivity and permeability of gases in glassy polymers, in Ingegneria chimica dell'ambiente e della sicurezza, Alma Mater StudiorumUniversità di Bologna, AMS Dottorato, 2015.

21 G. Genduso, B. S. Ghanem and I. Pinnau, Membranes, 2019, 9, 10 .

22 G. Genduso, Y. Wang, B. S. Ghanem and I. Pinnau, J. Membr. Sci., 2019, 584, 100-109.

23 E. Ricci, F. M. Benedetti, M. E. Dose, M. G. De Angelis, B. D. Freeman and D. R. Paul, J. Membr. Sci., 2020, 612, 118374.

24 G. Genduso and I. Pinnau, J. Membr. Sci., 2020, 610, 118269. 25 R. D. Raharjo, B. D. Freeman, D. R. Paul, G. C. Sarti and E. S. Sanders, J. Membr. Sci., 2007, 306, 75-92.

26 G. Genduso, E. Litwiller, X. Ma, S. Zampini and I. Pinnau, J. Membr. Sci., 2019, 577, 195-204.

27 H. D. Kamaruddin and W. J. Koros, J. Membr. Sci., 1997, 135, 147-159.

28 C. P. Ribeiro and B. D. Freeman, Polymer, 2010, 51, 11561168.

29 E. S. Sanders, W. J. Koros, H. B. Hopfenberg and V. T. Stannett, J. Membr. Sci., 1984, 18, 53-74.

30 E. S. Sanders and W. J. Koros, J. Polym. Sci., Part B: Polym. Phys., 1986, 24, 175-188.

31 E. Ricci, F. M. Benedetti, A. Noto, T. C. Merkel, J. Jin and M. Grazia De Angelis, Chem. Eng. J., 2021, 130715.

32 Y. Liu, Z. Chen, W. Qiu, G. Liu, M. Eddaoudi and W. J. Koros, J. Membr. Sci., 2021, 627, 119201.

33 Y. Liu, G. Liu, C. Zhang, W. Qiu, S. Yi, V. Chernikova, Z. Chen, Y. Belmabkhout, O. Shekhah, M. Eddaoudi and W. Koros, Adv. Sci., 2018, 5, 1800982.

34 R. Swaidan, B. Ghanem, E. Litwiller and I. Pinnau, J. Membr. Sci., 2015, 475, 571-581.

35 F. Alghunaimi, B. Ghanem, N. Alaslai, M. Mukaddam and I. Pinnau, J. Membr. Sci., 2016, 520, 240-246.

36 M. L. Jue and R. P. Lively, React. Funct. Polym., 2015, 86, 88110.

37 K. Ghosal, R. T. Chern, B. D. Freeman, W. H. Daly and I. I. Negulescu, Macromolecules, 1996, 29, 4360-4369.

38 N. Du, H. B. Park, G. P. Robertson, M. M. Dal-Cin, T. Visser, L. Scoles and M. D. Guiver, Nat. Mater., 2011, 10, 372-375.

39 X. Weng, J. E. Baez, M. Khiterer, M. Y. Hoe, Z. Bao and K. J. Shea, Angew. Chem., 2015, 54, 11214-11218.

40 K. Mizrahi Rodriguez, A. X. Wu, Q. Qian, G. Han, S. Lin, F. M. Benedetti, H. Lee, W. S. Chi, C. M. Doherty and Z. P. Smith, Macromolecules, 2020, 53, 6220-6234.

41 N. Du, G. P. Robertson, J. Song, I. Pinnau and M. D. Guiver, Macromolecules, 2009, 42, 6038-6043.

42 J. W. Jeon, D. G. Kim, E. H. Sohn, Y. Yoo, Y. S. Kim, B. G. Kim and J. C. Lee, Macromolecules, 2017, 50, 80198027.

43 C. R. Mason, L. Maynard-Atem, N. M. Al-Harbi, P. M. Budd, P. Bernardo, F. Bazzarelli, G. Clarizia and J. C. Jansen, Macromolecules, 2011, 44, 6471-6479. 
44 C. R. Mason, L. Maynard-Atem, K. W. J. Heard, B. Satilmis, P. M. Budd, K. Friess, M. Lanci, P. Bernardo, G. Clarizia and J. C. Jansen, Macromolecules, 2014, 47, 1021-1029.

45 W.-H. Wu, P. Thomas, P. Hume and J. Jin, Membranes, 2018, 8, 20.

46 B. Satilmis, M. Lanč, A. Fuoco, C. Rizzuto, E. Tocci, P. Bernardo, G. Clarizia, E. Esposito, M. Monteleone, M. Dendisová, K. Friess, P. M. Budd and J. C. Jansen, J. Membr. Sci., 2018, 555, 483-496.

47 L. M. Robeson, J. Membr. Sci., 2008, 320, 390-400.

48 K. Mizrahi Rodriguez, S. Lin, A. X. Wu, G. Han, J. J. Teesdale, C. M. Doherty and Z. P. Smith, Angew. Chem., 2021, 133, 6667-6673.

49 R. Swaidan, B. Ghanem, E. Litwiller and I. Pinnau, Macromolecules, 2015, 48, 6553-6561.

50 K. L. Gleason, Z. P. Smith, Q. Liu, D. R. Paul and B. D. Freeman, J. Membr. Sci., 2015, 475, 204-214.

51 E. Ricci and M. G. De Angelis, Membranes, 2019, 9, 8.

52 S. Wang, N. L. Pomerantz, Z. Dai, W. Xie, E. E. Anderson, T. Miller, S. A. Khan and G. N. Parsons, Mater. Today Adv., 2020, 8, 100085.

53 G. H. Fredrickson and E. Helfand, Macromolecules, 1985, 18, 2201-2207.

54 D. R. Paul, J. Polym. Sci., Part A-2: Polym. Phys., 1969, 7, 1811-1818.

55 S. Matteucci, Y. Yampolskii, B. D. Freeman and I. Pinnau, Transport of gases and vapors in glassy and rubbery polymers, in Materials Science of Membranes for Gas and Vapor Separation, ed. Y. Yampolskii, I. Pinnau, B. Freeman, 2006, pp. 1-47.

56 H. W. H. Lai, F. M. Benedetti, Z. Jin, Y. C. Teo, A. X. Wu, M. G. De Angelis, Z. P. Smith and Y. Xia, Macromolecules, 2019, 52, 6294-6302.

57 Z. P. Smith, D. F. Sanders, C. P. Ribeiro, R. Guo, B. D. Freeman, D. R. Paul, J. E. McGrath and S. Swinnea, J. Membr. Sci., 2012, 415-416, 558-567.

58 W. J. Koros, J. Polym. Sci., Part A-2: Polym. Phys., 1980, 18, 981-992.

59 W. J. Koros, R. T. Chern, V. Stannett and H. B. Hopfenberg, J. Polym. Sci., Part A-2: Polym. Phys., 1981, 19, 1513-1530.

60 M. D. Koretsky, Engineering and Chemical Thermodynamics, John Wiley \& Sons, 2012.

61 J. G. Wijmans and R. W. Baker, J. Membr. Sci., 1995, 107, 121.

62 B. D. Freeman, Macromolecules, 1999, 32, 375-380.

63 Z. X. Low, P. M. Budd, N. B. McKeown and D. A. Patterson, Chem. Rev., 2018, 118, 5871-5911.

64 R. R. Tiwari, J. Jin, B. D. Freeman and D. R. Paul, J. Membr. Sci., 2017, 537, 362-371.

65 M. L. Jue, V. Breedveld and R. P. Lively, J. Membr. Sci., 2017, 530, 33-41.

66 Y. Huang and D. R. Paul, J. Polym. Sci., Part B: Polym. Phys., 2007, 45, 1390-1398.

67 M. Lanč, K. Pilnáček, C. R. Mason, P. M. Budd, Y. Rogan, R. Malpass-Evans, M. Carta, B. C. Gándara, N. B. McKeown, J. C. Jansen, O. Vopička and K. Friess, J. Membr. Sci., 2019, 570-571, 522-536.
68 R. Swaidan, X. Ma, E. Litwiller and I. Pinnau, J. Membr. Sci., 2013, 447, 387-394.

69 A. X. Wu, J. A. Drayton, K. Mizrahi Rodriguez, F. M. Benedetti, Q. Qian, S. Lin and Z. P. Smith, Macromolecules, 2021, 54, 22-34.

70 W. J. Koros, D. R. Paul and G. S. Huvard, Polymer, 1979, 20, 956-960.

71 S. Yadvika, T. R. Sreekrishnan, S. Kohli and V. Rana, Bioresour. Technol., 2004, 95, 1-10.

72 M. Galizia, W. S. Chi, Z. P. Smith, T. C. Merkel, R. W. Baker and B. D. Freeman, Macromolecules, 2017, 50, 7809-7843.

73 Y. Yampolskii, I. Pinnau and B. D. Freeman, Materials Science of Membranes for Gas and Vapor Separation, John Wiley \& Sons, Ltd, Chichester, UK, 2006.

74 N. Du, G. P. Robertson, M. M. Dal-Cin, L. Scoles and M. D. Guiver, Polymer, 2012, 53, 4367-4372.

75 V. Loianno, S. Luo, Q. Zhang, R. Guo and M. Galizia, J. Membr. Sci., 2019, 574, 100-111.

76 F. Doghieri and G. C. Sarti, Macromolecules, 1996, 29, 78857896.

77 M. Minelli, S. Campagnoli, M. G. De Angelis, F. Doghieri and G. C. Sarti, Macromolecules, 2011, 44, 4852-4862.

78 H. Yin, Y. Z. Chua, B. Yang, C. Schick, W. J. Harrison, P. M. Budd, M. Böhning and A. Schönhals, J. Phys. Chem. Lett., 2018, 9, 2003-2008.

79 H. Yin, B. Yang, Y. Z. Chua, P. Szymoniak, M. Carta, R. Malpass-Evans, N. B. McKeown, W. J. Harrison, P. M. Budd, C. Schick, M. Böhning and A. Schönhals, ACS Macro Lett., 2019, 8, 1022-1028.

80 O. Vopička, M. G. De Angelis, N. Du, N. Li, M. D. Guiver and G. C. Sarti, J. Membr. Sci., 2014, 459, 264-276.

81 R. W. Baker and K. Lokhandwala, Ind. Eng. Chem. Res., 2008, 47, 2109-2121.

82 N. Alaslai, B. Ghanem, F. Alghunaimi, E. Litwiller and I. Pinnau, J. Membr. Sci., 2016, 505, 100-107.

83 X. Ma, R. Swaidan, Y. Belmabkhout, Y. Zhu, E. Litwiller, M. Jouiad, I. Pinnau and Y. Han, Macromolecules, 2012, 45, 3841-3849.

84 R. Swaidan, B. S. Ghanem, E. Litwiller and I. Pinnau, J. Membr. Sci., 2014, 457, 95-102.

85 Z. Tian, B. Cao and P. Li, J. Membr. Sci., 2018, 560, 87-96.

86 A. M. Kratochvil and W. J. Koros, Macromolecules, 2008, 41, 7920-7927.

87 W. Qiu, C. C. Chen, L. Xu, L. Cui, D. R. Paul and W. J. Koros, Macromolecules, 2011, 44, 6046-6056.

88 J. D. Wind, C. Staudt-Bickel, D. R. Paul and W. J. Koros, Ind. Eng. Chem. Res., 2002, 41, 6139-6148.

89 C. Zhang, L. Fu, Z. Tian, B. Cao and P. Li, J. Membr. Sci., 2018, 556, 277-284.

90 Z. Liu, Y. Liu, W. Qiu and W. J. Koros, Angew. Chem., 2020, 59, 14877-14883.

91 M. A. Abdulhamid, G. Genduso, Y. Wang, X. Ma and I. Pinnau, Ind. Eng. Chem. Res., 2020, 59, 5247-5256.

92 J. Wu, J. Liu and T. S. Chung, Adv. Sustainable Syst., 2018, 2, 1800044.

93 A. Fuoco, B. Satilmis, T. Uyar, M. Monteleone, E. Esposito, C. Muzzi, E. Tocci, M. Longo, M. P. De Santo, M. Lanč, 
K. Friess, O. Vopička, P. Izák and J. C. Jansen, J. Membr. Sci., 2020, 594, 117460.

94 Q. Song, S. Cao, R. H. Pritchard, B. Ghalei, S. A. AlMuhtaseb, E. M. Terentjev, A. K. Cheetham and E. Sivaniah, Nat. Commun., 2014, 5, 4813.

95 F. Y. Li, Y. Xiao, Y. K. Ong and T. S. Chung, Adv. Energy Mater., 2012, 2, 1456-1466.

96 X. Wu, Y. Ren, G. Sui, G. Wang, G. Xu, L. Yang, Y. Wu, G. He, N. Nasir, H. Wu and Z. Jiang, AIChE J., 2020, 66, e16800.

97 K. R. Vijisha and K. Muraleedharan, Int. J. Greenhouse Gas Control, 2017, 58, 62-70.

98 G. Han, Q. Qian, K. Mizrahi Rodriguez and Z. P. Smith, Ind. Eng. Chem. Res., 2020, 59, 7888-7900.
99 G. Han, K. M. Rodriguez, Q. Qian and Z. P. Smith, Ind. Eng. Chem. Res., 2020, 59, 18139-18150.

100 S. Couck, J. F. M. Denayer, G. V. Baron, T. Rémy, J. Gascon and F. Kapteijn, J. Am. Chem. Soc., 2009, 131, 6326-6327.

101 R. Vaidhyanathan, S. S. Iremonger, G. K. H. Shimizu, P. G. Boyd, S. Alavi and T. K. Woo, Science, 2010, 330, 650-653.

102 C. H. Lau, K. Konstas, C. M. Doherty, S. J. D. Smith, R. Hou, H. Wang, M. Carta, H. Yoon, J. Park, B. D. Freeman, R. Malpass-Evans, E. Lasseuguette, M. C. Ferrari, N. B. McKeown and M. R. Hill, Nanoscale, 2020, 12, 17405-17410. 